\title{
Screening for a raised rectal temperature in Africa
}

\author{
Robert J Jones, Tim J O’Dempsey, Brian M Greenwood
}

\begin{abstract}
The main purpose of this study was to compare rectal and axillary temperature measurements in African children. Altogether 573 sick children were seen in an outpatient setting in rural West Africa. Rectal and axillary temperatures were measured and the parent or guardian was asked if they thought that the child had a raised body temperature. Normal ranges were defined from an age matched population of 203 healthy children.

A raised axillary temperature predicted a raised rectal temperature with a sensitivity of $98 \%$ and a specificity of $88 \%$. The parents' impression that their child had a fever was a less sensitive $(89 \%)$ and less specific $(59 \%)$ indicator of raised rectal temperature.
\end{abstract}

A raised axillary temperature is a good screening test for a raised rectal temperature in African children.

(Arch Dis Child 1993; 69: 437-439)

Raised body temperature is an important sign of childhood illness. ${ }^{1}$ It is generally considered that rectal temperature measurement is a more accurate method for assessing the presence or absence of a fever than axillary or sublingual methods, ${ }^{2}$ but measuring rectal temperature may be hazardous. ${ }^{3}$ The following study compares temperature measurements made in the rectum and the axilla in a group of West African children. It also assesses the validity of the parent or guardian's impression of body temperature as a predictor of raised rectal temperature.

\section{Methods}

SELECTION OF SICK CHILDREN

Five hundred and seventy three sick children under 5 years of age were selected from outpatient clinics at a rural health centre in The Gambia, West Africa. All those who presented before 11 am to general outpatient clinics and the first 20 presenting to clinics for those under 5 years were included. In each case the episode investigated was the child's first visit to the health centre with that illness. Children previously seen and treated elsewhere were excluded. Recruitment was carried out for four weeks in August and one week in midSeptember, 1992.

\section{SELECTION OF HEALTHY CHILDREN}

One hundred and two cases living within a $4 \mathrm{~km}$ radius of the health centre were randomly chosen from the 447 sick children who presented during August. The home of each was visited and two healthy children from each home or a nearby house were invited to participate. Two hundred and three children aged less than 5 years who were healthy according to the parent or guardian were selected to represent the age distribution of the population of sick children. Recruitment of healthy children took place during the first two weeks of September.

The study was undertaken at the height of the rainy season when many febrile children have malaria. The ambient temperature during the time of the study ranged from $24^{\circ} \mathrm{C}$ to $36^{\circ} \mathrm{C}$.

\section{EXAMINATION}

Each child was examined outside in the presence of the parent (or guardian). The parent was asked 'does your child have a hot body now?' by a field worker using standardised translations in the appropriate local language. The parent of each sick child had previously had the opportunity to volunteer a history of fever. Rectal and left axillary temperatures were measured simultaneously using digital thermometers (MT-300-C 1, E H Zeal Ltd, London). Thermometers were used according to the manufacturer's instructions and the same pair of thermometers were used in all cases. The rectal thermometer was cleaned with spirit between measurements and was inserted up to a mark $2 \cdot 3 \mathrm{~cm}$ along its shaft. The height and weight of each sick child was measured.

Examination of sick and healthy children took place between 9 am and $3 \mathrm{pm}$.

\section{Results}

The mean (SD) values for rectal and axillary temperature among the 203 well children were $37.3(0.50)^{\circ} \mathrm{C}$ and $36.6(0.43)^{\circ} \mathrm{C}$ respectively. Normal ranges, defined as the mean (2 SD), were $36.3^{\circ} \mathrm{C}-38.3^{\circ} \mathrm{C}$ for rectal temperature and $35.7^{\circ} \mathrm{C}-37.4^{\circ} \mathrm{C}$ for axillary temperature.

The mean (SD) difference between the rectal and axillary temperature measurements was $0.73(0.49)^{\circ} \mathrm{C}$. The figure shows the Bland-Altman distribution of the difference between the two measurements against the mean of the two measurements for the sick children. This does not assume that either method is more accurate in assessing body temperature. ${ }^{4}$ There was no significant correlation between body temperature (defined as the mean of rectal and axillary measurements) and the difference between these two readings $(r=-0.02 ; 95 \%$ confidence interval $(\mathrm{CI})-0 \cdot 1$ to 0.06 ).

A raised rectal temperature was defined as one greater than $38.3^{\circ} \mathrm{C}$ and a raised axillary 
temperature as one greater than $37 \cdot 4^{\circ} \mathrm{C}$. Altogether 172 of 175 children with a raised rectal temperature also had a raised axillary temperature (sensitivity 98\%). Three hundred and fifty two of 398 children without a raised rectal temperature did not have a raised axillary temperature (specificity $88 \%$ ). The parents of 164 of the 175 children with a raised rectal temperature volunteered a history of fever $(94 \%$ sensitivity) but only 96 parents of 397 children without a raised rectal temperature did not volunteer a history of fever (24\% specificity). When the parents were asked whether they thought their child currently had a hot body,

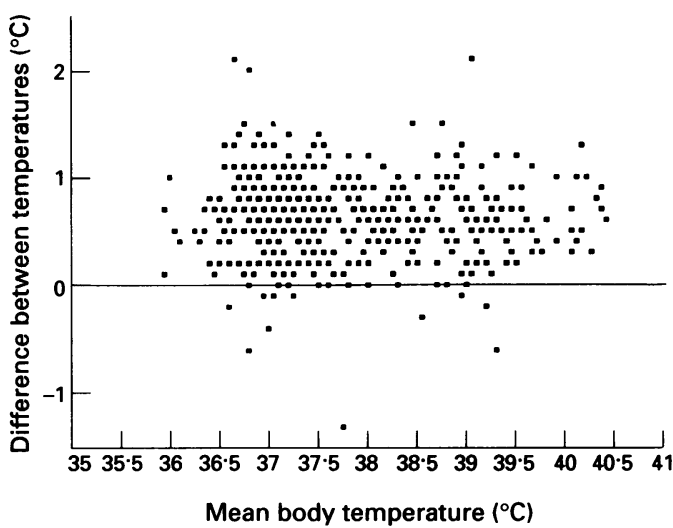

Difference between rectal and axillary temperature against mean temperature for all sick children (each point may represent more than one case).

Table 1 Axillary temperature compared with rectal temperature

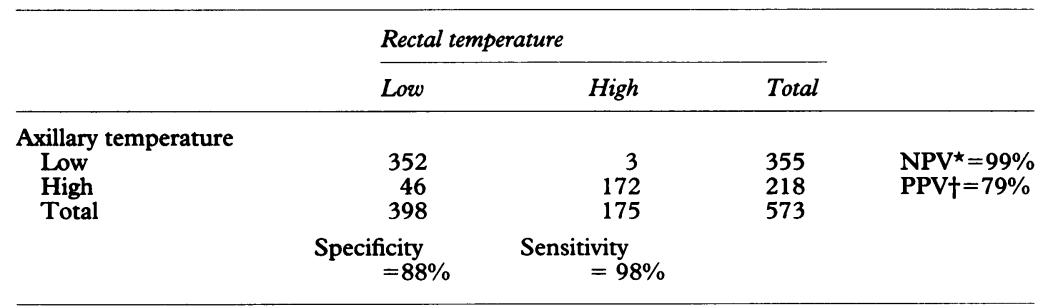

*The negative predictive value (NPV) of a low axillary temperature.

tThe positive predictive value (PPV) of a high axillary temperature.

Table 2 Parents' volunteered history of fever compared with rectal temperature

\begin{tabular}{|c|c|c|c|c|}
\hline & \multicolumn{3}{|c|}{ Rectal temperature } & \\
\hline & Low & High & Total & \\
\hline $\begin{array}{c}\text { Voluntee } \\
\text { Low } \\
\text { High } \\
\text { Total }\end{array}$ & $\begin{array}{r}96 \\
301 \\
397\end{array}$ & $\begin{array}{r}11 \\
164 \\
175\end{array}$ & $\begin{array}{l}107 \\
465 \\
572\end{array}$ & $\begin{array}{l}\mathrm{NPV}^{\star}=90 \% \\
\mathrm{PPV}^{\prime}=35 \%\end{array}$ \\
\hline & $\begin{array}{l}\text { Specificity } \\
=24 \%\end{array}$ & $\begin{array}{l}\text { Sensitivity } \\
=94 \%\end{array}$ & & \\
\hline
\end{tabular}

*The negative predictive value (NPV) of no volunteered history of fever. tThe positive predictive value (PPV) of a volunteered history or fever.

Table 3 Parents' impression of body temperature compared with rectal temperature

\begin{tabular}{|c|c|c|c|c|}
\hline & \multicolumn{3}{|c|}{ Rectal temperature } & \\
\hline & Low & High & Total & \\
\hline \multirow[t]{2}{*}{$\begin{array}{c}\text { Parents' } \\
\text { Low } \\
\text { High } \\
\text { Total }\end{array}$} & $\begin{array}{l}233 \\
165 \\
398\end{array}$ & $\begin{array}{r}20 \\
155 \\
175\end{array}$ & $\begin{array}{l}355 \\
320 \\
573\end{array}$ & $\begin{array}{l}\mathrm{NPV}^{\star}=92 \% \\
\text { PPV } \dagger=48 \%\end{array}$ \\
\hline & $\begin{array}{l}\text { Specificity } \\
=59 \%\end{array}$ & $\begin{array}{l}\text { Sensitivity } \\
=89 \%\end{array}$ & & \\
\hline
\end{tabular}

*The negative predictive value (NPV) of parents' impression of low body temperature. tThe positive predictive value (PPV) of parents' impression of high body temperature.
155 of 175 children with a high rectal temperature answered positively ( $89 \%$ sensitivity). Two hundred and thirty three of 398 without a high rectal temperature answered negatively (59\% specificity). These data are shown in tables 1-3.

The weight for height centile for each sick child was calculated using the nutritional anthropometry program of Epi Info. ${ }^{5}$ The mean (SD) weight for height centile was $22 \cdot 6$ $(26.6) \%$. The mean (SD) difference between axillary and rectal temperature readings for the 143 children with weight for height centile readings below the lower quartile value $(<2.03 \%)$ was $0.57(0.35)^{\circ} \mathrm{C}$ while for the 143 children with readings above the upper quartile value $(>36.13 \%)$ it was $0.68(0.32)^{\circ} \mathrm{C}$. There was a significant difference between the means of the two groups of $0.11^{\circ} \mathrm{C}\left(95 \%\right.$ CI $0.04^{\circ} \mathrm{C}$ to $0 \cdot 19^{\circ} \mathrm{C}$ ).

\section{Discussion}

A distinction should be made between using a measurement as a screening test and using it as a definitive measurement. In the case of temperature measurement it is sometimes desirable to have a definitive measurement, for example to chart the course of an infection and its response to treatment. However, a worried parent or a primary health worker uses measurement of temperature to determine whether or not a child is febrile, in other words they are screening for raised body temperature.

The data presented here indicate that measurement of axillary temperature is a good screen for a raised body temperature (as defined by a raised rectal temperature). Although the difference between rectal and axillary temperatures appears not to be related to body temperature (figure) the wide range of this difference suggests that axillary temperature cannot be used as an accurate estimate of rectal temperature by adding a constant.

In a similar study of infants in Australia and the UK, Morley et al found that raised axillary temperature predicted raised rectal temperature with a sensitivity of $73 \%$ and a specificity of $94 \%{ }^{6}$ Other studies agree with their conclusion that axillary temperature measurement is a poor screening test for raised rectal temperature. ${ }^{78}$ There are a number of possible reasons why the data presented here differ from these previous data. Firstly, tropical diseases such as malaria are associated with very high fevers. The axillary method is more likely to identify correctly those with a very high fever than those whose fever is only moderate. Secondly, children with a low weight for height were found to have a smaller difference between rectal and axillary temperature and in this study population the average weight for height centile was considerably below the 50th centile. Thus axillary temperature measurement may be more accurate in undernourished children than in the well nourished. Finally, high ambient temperature may also result in a higher axillary temperature relative to rectal temperature as has been found for temperature measurement at other sites. ${ }^{9}$ Two other reports from tropical countries conclude that axillary temperature is a 
good screen for raised rectal temperature. ${ }^{1011}$

A study in India of the parents' impression of whether or not a child has a fever reported a similar sensitivity (89\%) and higher specificity $(89 \%)$ than the present study. ${ }^{12}$ The accuracy of this method is likely to be highly dependent upon factors such as the exact meaning of the words used when asking the question and the emphasis that parents put on the importance of fever as a symptom.

The presence or absence of a fever should not be the only factor in assessing whether a child is sick or well. However, where health resources are limited it is often necessary to perform a basic field assessment of a child's health. In a tropical country, the presence or absence of a raised body temperature is likely to be an important part of this screening process. Axillary temperature measurement has also been used for active case detection in malaria vaccine trials. ${ }^{13}$ These data indicate that a raised axillary temperature is a good indicator of raised body temperature and thus of a child who needs further evaluation.

The authors thank Mr J Todd, Mr O Krubally, Mr B Singateh, Mr G Touray, Mr G Fegan, all the staff at MRC Basse and Basse Health Centre and the Doctor Robert Malcolm Trust.
1 Morley CJ, Thornton AJ, Cole TJ, Fowler MA, Hewson PH. Symptoms and signs in infants younger than 6 months of age correlated with the severity of their illness. Pediatrics 1991; 88: 1119-24.

2 Lorin MI. Fever: pathogenesis and treatment. In: Feigin $\mathrm{RD}$, Cherry JD, eds. Textbook of pediatric infectious diseases. Philadelphia: WB Saunders, 1987: 150

3 Anonymous. Hazards of temperature taking. BMF 1970; ii: 4-5.

4 Bland JM, Altman DG. Statistical methods for assessing agreement between two methods of clinical measurement. Lancet 1986; i: 307-10.

5 Dean AD, Dean JA, Burton JH, Dicker RC. Epi Info, version 5: a word processing, database, and statistics program for epidemiology on microcomputers. Atlanta: Centers for epidemiology on microcom

6 Morley CJ, Hewson PH, Thornton AJ, Cole TJ. Axillary and rectal temperature measurements in infants. Arch Dis Child 1992; 67: 122-5. 7 Weisse ME, Reagen MS, Boule L, France N. Axillary vs
rectal temperature in ambulatory and hospitalized children. Pediat Infect Dis $\mathcal{7} 1991$; 10: 541-2.

8 Ogren JM. The inaccuracy of axillary temperature measured with an electronic thermometer. Am $\mathcal{F}$ Dis Child 1990; 144: 109-11.

9 Zehner WJ, Terndrup TE. The impact of moderate ambient temperature variance on the relationship between oral, rectal and tympanic membrane temperatures. Clin Pediatr (Phila) 1991; 30 (4 suppl): 61-4.

10 Shann F, Mackenzie A. Axillary or rectal temperatures in children? Lancet 1981; ii: 310.

11 Akinbami FO, Sowunmi A. Body temperature in the Nigerian neonate - comparison of axillary and rectal temperatures. Afr f Med Med Sci 1991; 20: 49-52.

12 Singhi S, Sood V. Reliability of subjective assessment of fever by mothers. Indian Pediatr 1990; 27: 811-5.

13 Valero MV, Amador LR, Galindo C, et al. Vaccination with SPf66, a chemically synthesised vaccine, against Plasmodium falciparum malaria in Colombia. Lancet 1993; 341: 705-10. 